\title{
Current Status of Nuclear Medicine Practice in Latin America and the Caribbean
}

\author{
Diana Páez ${ }^{1}$, Pilar Orellana ${ }^{2}$, Claudia Gutiérrez ${ }^{3}$, Raúl Ramirez ${ }^{4}$, Fernando Mut ${ }^{5}$, and Leonel Torres ${ }^{6}$ \\ ${ }^{I}$ Nuclear Medicine and Diagnostic Imaging Section, Division of Human Health, International Atomic Energy Agency, Vienna, \\ Austria; ${ }^{2}$ Nuclear Medicine Unit, Radiology Department, Pontificia Universidad Catolica de Chile, Santiago, Chile; ${ }^{3}$ Cardiology \\ Institute, Fundacion CardioInfantil, Bogota, Colombia; ${ }^{4}$ Latin America Section, Department of Technical Cooperation, International \\ Atomic Energy Agency, Vienna, Austria; ${ }^{5}$ Nuclear Medicine Service, Asociacion Española, Montevideo, Uruguay; and ${ }^{6}$ Clinical \\ Research Laboratory, CENTIS, Havana, Cuba
}

The practice of nuclear medicine (NM) in the Latin American and Caribbean region has experienced important growth in the last decade. However, there is great heterogeneity among countries regarding the availability of technology and human resources. According to data collected through June 2014 by the International Atomic Energy Agency (IAEA), the total number of $y$ cameras in the region is 1,231 , with an average of 2.16 per million inhabitants. Over $90 \%$ of the equipment is SPECT cameras; $7.6 \%$ of which have hybrid technology. There are 161 operating PET or PET/CT cameras in 12 member states, representing a rate of 0.3 per million people. Most NM centers belong to the private health system and are in capitals or major cities. Only 4 countries have the capability of assembling ${ }^{99}$ Mo-99mTc generators, and 2 countries produce ${ }^{99 \mathrm{~m} T c}$ from nuclear reactors. Cold kits are produced in some countries, and therapeutic agents are mostly imported from outside the region. There are 35 operative cyclotrons. In relation to human resources: there is 1 physician per y camera, 1.6 technologists per y camera, 0.1 medical physicist per center, and approximately 0.1 radiochemist or radiopharmacist per center. Nearly $94 \%$ of the procedures are diagnostic. PET studies represent about $4 \%$ of the total. The future of NM in the Latin American and Caribbean region is promising, with great potential and possibilities. Some of the most important factors driving the region toward greater homogeneity in the availability and application of NM, and bridging the gaps between countries, are clinician awareness of the importance of NM in managing diseases prevalent in the region, increased building of capacity, continuous and strong support from international organizations such as the IAEA through national and regional projects, and strong public-private partnerships and government commitment.

Key Words: nuclear medicine; SPECT; PET; Latin America; radionuclides

J Nucl Med 2015; 56:1629-1634

DOI: 10.2967/jnumed.114.148932

G eographically, Latin America and the Caribbean refer to the whole of the American continent below the Rio Grande river,

Received Oct. 14, 2014; revision accepted May 5, 2015.

For correspondence or reprints contact: Pilar Orellana, Nuclear Medicine Unit, Radiology Department, Pontificia Universidad Catolica de Chile, Santiago, Chile, Marcoleta 367. Santiago de Chile.

E-mail: porellana@med.puc.cl

Published online Jul. 30, 2015

COPYRIGHT (C 2015 by the Society of Nuclear Medicine and Molecular Imaging, Inc. including Mexico, Central America, the Caribbean islands, and South America. This region has a total population of over 600 million, with almost $80 \%$ concentrated in urban areas. Literacy is above $91 \%$, life expectancy reaches a mean of $75 \mathrm{y}$, and the population is growing at an average of $1.1 \%$ annually (1). Public expenditure in health care as a percentage of gross national product varies between 4.4 and 10.9 (2).

In the last few decades, the Latin American and Caribbean region has experienced several social, demographic, and economic changes that have had a significant impact on public health. Population aging and lifestyle changes exert great pressure on the health care system through the increasing prevalence of chronic diseases affecting elderly people. According to the 2012 statistics from the Pan American Health Organization, the main causes of death in the region are cardiovascular diseases (especially ischemic cardiomyopathy) and several types of cancer (especially lung, prostate, breast, and cervix, among others). Of the deaths registered in the region, these two causes account for about 50\%, followed by accidents and criminal violence (3). In this context, diagnostic and therapeutic application of nuclear medicine (NM) techniques gains vital importance and can be of great impact in the cost-effective management of most of these patients.

The goal of this report is to evaluate and describe the current status of NM practice in International Atomic Energy Agency (IAEA) Member States that participated in the Regional Technical Cooperation Agreement for the Promotion of Nuclear Science and Technology in Latin America and the Caribbean Region (ARCAL). Data were obtained until June 2014 from the IAEA's Nuclear Medicine Database (NUMDAB), as well as from the participants of coordination meetings for several ongoing regional projects, the Regional Strategic Profile (4), and the opinions of various NM experts and consultants in the region.

\section{TECHNOLOGY}

The approximate total number of $\gamma$ cameras in the region is 1,231, with Brazil and Mexico having the largest number (360 and 285, respectively). Haiti, in contrast, has no NM services (Table 1).

The number of operating $\gamma$ cameras per million inhabitants ranges from 0.0 to 6.7, with an average of 2.16 for the whole region; Argentina, Uruguay, and Chile have the highest ratio, followed by Mexico and Panama (Fig. 1).

The technologic characteristics of the installed equipment are quite variable (Table 1). There is still some proportion of planar $\gamma$ 
TABLE 1

Technologic Resources for NM Imaging in Latin American and Caribbean IAEA ARCAL Countries

\begin{tabular}{|c|c|c|c|c|c|c|c|}
\hline \multirow[b]{2}{*}{ Country } & \multirow[b]{2}{*}{ Population (millions) } & \multirow[b]{2}{*}{ NM centers } & \multicolumn{4}{|c|}{ y cameras } & \multirow[b]{2}{*}{ PET cameras } \\
\hline & & & Planar & SPECT & Hybrid & Total & \\
\hline Argentina & 40.3 & 295 & 48 & 214 & 8 & 270 & 23 \\
\hline Bolivia & 9.9 & 6 & 3 & 8 & 0 & 11 & 0 \\
\hline Brazil & 193.7 & 380 & 0 & 330 & 30 & 360 & 68 \\
\hline Chile & 17 & 44 & 4 & 45 & 6 & 55 & 10 \\
\hline Colombia & 45.7 & 80 & 0 & 78 & 4 & 82 & 9 \\
\hline Costa Rica & 4.6 & 6 & 2 & 7 & 0 & 9 & 1 \\
\hline Cuba & 11.2 & 15 & 1 & 13 & 1 & 15 & 1 \\
\hline Ecuador & 13.6 & 8 & 1 & 3 & 3 & 7 & 2 \\
\hline El Salvador & 6.1 & 2 & 0 & 2 & 0 & 2 & 0 \\
\hline Guatemala & 14 & 10 & 4 & 3 & 0 & 7 & 0 \\
\hline Haiti & 10 & 0 & 0 & 0 & 0 & 0 & 0 \\
\hline Honduras & 7.5 & 2 & 0 & 2 & 0 & 2 & 0 \\
\hline Jamaica & 2.7 & 2 & 1 & 1 & 0 & 2 & 0 \\
\hline Mexico & 116 & 200 & 0 & 260 & 25 & 285 & 35 \\
\hline Nicaragua & 5.7 & 1 & 0 & 1 & 0 & 1 & 0 \\
\hline Panama & 3.4 & 7 & 0 & 3 & 4 & 7 & 1 \\
\hline Paraguay & 6.3 & 4 & 0 & 5 & 0 & 5 & 1 \\
\hline Peru & 29.1 & 36 & 2 & 35 & 2 & 39 & 3 \\
\hline Dominican Republic & 10 & 11 & 1 & 12 & 0 & 13 & 1 \\
\hline Uruguay & 3.4 & 8 & 0 & 14 & 3 & 17 & 2 \\
\hline Venezuela & 28.6 & 34 & 13 & 28 & 1 & 42 & 6 \\
\hline Total & 571.8 & 1,141 & 80 & 1,064 & 87 & 1,231 & 161 \\
\hline
\end{tabular}

cameras: about $6 \%$, with most having surpassed the usual life span recommended by the manufacturers (5). However, a few of these cameras are near-state-of-the-art equipment, such as dedicated thyroid cameras or other small-field-of-view instruments designed for specific imaging procedures. On the other hand, in countries such as Brazil, Chile, Colombia, and Uruguay, SPECT technology is clearly dominant or nearly exclusive. In total, about $93.5 \%$ of the instruments in the region are SPECT cameras, of which $7.6 \%$ use hybrid technology (SPECT/CT). Currently, the region has a high rate of replacing outdated technology, with increasing numbers of SPECT and SPECT/CT cameras ( 6 ).

Twelve of the 21 ARCAL Member States have PET or PET/CT equipment, for a total of 161 operating instruments, $90 \%$ of which are PET/CT systems (Fig. 2). During the last $5 \mathrm{y}$, a significant increase in the number of installed PET machines has been seen, with a growth of $88 \%$ between 2006 and 2009, 35\% between 2009 and 2011 , and $31 \%$ between 2011 and 2013 .

The largest number of NM centers belongs to the private sector ( $\sim 70 \%$ ), despite the fact that health care is provided for most of the population by the public system. Regarding geographic distribution, in all countries NM facilities tend to be concentrated in capitals and large urban communities.

\section{RADIOPHARMACY}

The development of radioisotope production and radiopharmaceuticals in Latin America and the Caribbean is heterogeneous.
Argentina, Brazil, Chile, Mexico, and Peru have nuclear reactors for research purposes, allowing the production of limited amounts of medical radioisotopes. Only 4 countries have the capability of assembling ${ }^{99} \mathrm{Mo}-{ }^{99 m} \mathrm{Tc}$ generators, namely Argentina, Brazil, Cuba, and Mexico, either through import of fission ${ }^{99}$ Mo or through local production (Argentina). Brazil is the major producer of generators, with 18,236 units produced in $2012(49 \%$ of the regional demand), followed by Argentina with 28\%, Mexico with $6 \%$, and Cuba with $2 \%$. Peru and Chile produce ${ }^{99 \mathrm{~m} T \mathrm{Tc} \text { from }}$ nuclear reactors.

As for the availability of cold kits for labeling with ${ }^{99 \mathrm{~m}} \mathrm{Tc}$, they are produced by public institutions in the case of Brazil, Chile, Cuba, Mexico, and Peru and by private companies in the case of Argentina, Brazil, Chile, and Uruguay. Most manufacturers commercialize these products in their own countries as well as in the rest of the region. Of the 19 cold kit compounds produced in the region, methylene diphosphonate accounts for 37\%, diethylenetriaminepentaacetic acid $16 \%$, sestamibi $15 \%$, dimercaptosuccinic acid $11 \%$, ethylcysteinate dimer and phytate $7 \%$, and pyrophosphate and dextran $4 \%$, whereas other formulations represent less than $10 \%$. Production usually follows international standards.

Most of the countries have radiopharmacy units at operational level 1 or 2, following the IAEA's classification criteria contained in the publication Operational Guidance on Hospital Radiopharmacy: A Safe and Effective Approach (7). Therapeutic agents are mostly imported from outside the region. ${ }^{131} \mathrm{I},{ }^{153} \mathrm{Sm}$, and ${ }^{66} \mathrm{Ho}$ are locally produced in Argentina, Brazil, Chile, Mexico, and Peru. 


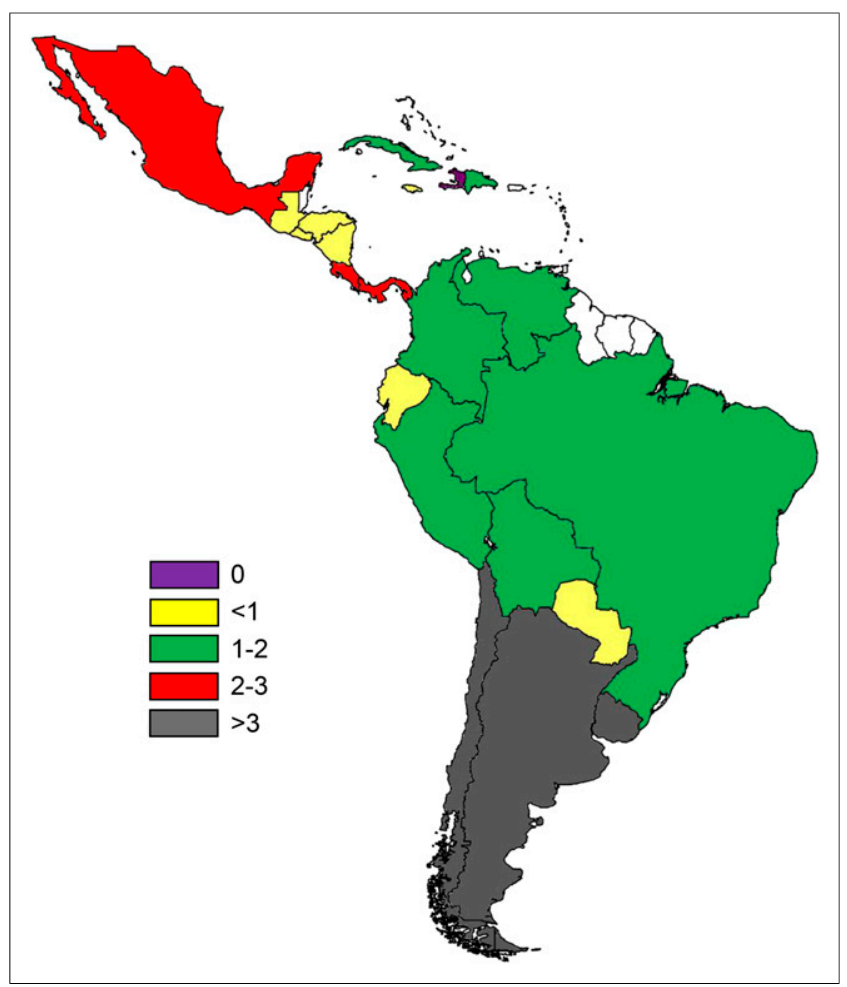

FIGURE 1. Y cameras per million population.

There are currently at least 35 operative cyclotrons in the region, with a $300 \%$ growth in installed capacity between 2006 and 2013. Regarding the production of PET isotopes, all of the above-mentioned cyclotrons are devoted to the production of ${ }^{18} \mathrm{~F}$ and few are equipped to produce ${ }^{11} \mathrm{C},{ }^{15} \mathrm{~N}$, or ${ }^{15} \mathrm{O}$. Over $90 \%$ of the PET procedures are performed with ${ }^{18} \mathrm{~F}$-FDG. However, there is increasing use of other ${ }^{18} \mathrm{~F}$-labeled tracers, such as thymidine, choline, dopamine, and acetate. ${ }^{68} \mathrm{Ge}-{ }^{68} \mathrm{Ga}$ generators were recently introduced for labeling of somatostatin peptide analogs and are already available in Argentina, Chile, Colombia, Mexico, and Uruguay.

\section{HUMAN RESOURCES AND EDUCATION}

\section{Nuclear Physicians}

There are approximately 1,264 NM physicians in the region; the number of physicians per $\gamma$ camera varies between 0.5 and 2.3, with an average of 1 (Fig. 3). Some NM physicians hold a second specialty, most frequently internal medicine, endocrinology, oncology, or cardiology. Recently, the introduction of hybrid modalities such as SPECT/CT and PET/CT has attracted radiologists to the field. Training of NM physicians in radiology is increasing.

Tertiary educational institutions with accredited programs for NM physicians are available in Argentina, Brazil, Colombia, Chile, Mexico, Peru, Uruguay, and Venezuela, conferring a specialization degree or diploma in NM. However, postdegree educational programs differ among these countries, being considered primary specializations in some, with a duration of 3-4 y, or as subspecialties of internal medicine or radiology in others, with an average duration of $2 \mathrm{y}$. In Venezuela, for example, training in this area is part of a broader program in radiation oncology involving radiotherapy and $\mathrm{NM}$.

\section{Technologists}

Although not critical, the shortage of technologists is a common problem in the region. The number of technologists per camera varies between 0.4 and 4.3, with an average of 1.6 (Fig. 3). The level of education and formal training is again quite varied across countries; formal university degrees can be obtained in Argentina, Brazil, Chile, Costa Rica, Cuba, Mexico, and Uruguay (8). In most cases, the training is not focused on NM only but covers other areas of radiation medicine such as radiology and radiotherapy. Uruguay is the only country with a specific university degree for NM technologists. Nevertheless, the number of formally trained technologists does not generally meet the demand, and many positions are filled by personnel with training in other biomedically related areas. In Brazil, for example, many technologist positions are occupied by licensed biologists or laboratory technicians, as is the case in Colombia, where bacteriologists have specific training in NM.

The increasing complexity of imaging equipment and software, as well as the introduction of hybrid technologies, creates a special challenge in human resources. To deal with this problem common to many Member States, the IAEA has introduced a worldwide distance-assisted training program for NM technologists, which includes a comprehensive set of online training resources covering basic sciences and clinical applications, with special attention to SPECT/CT and PET/CT (8). The program adopts a distance-learning approach to be conducted in the participating countries and is designed to allow students to learn and practice at their own pace under the supervision of a network of local professionals who provide support. In the case of Latin America, the program (originally in English) has been translated into Spanish and is accessible to all countries in the region, including Brazil, where the native language is Portuguese. Courses have already been conducted or are in progress in most countries in the region; currently there are more than 200 students in 12 countries actively participating in the

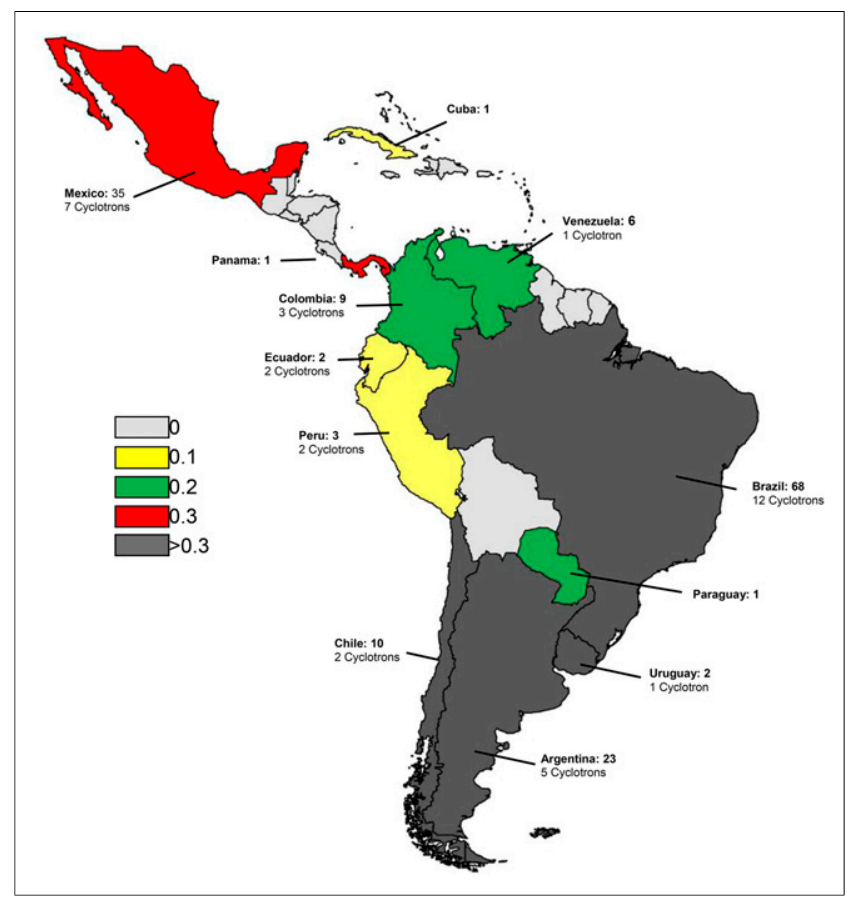

FIGURE 2. PET and PET/CT systems installed in the region. 


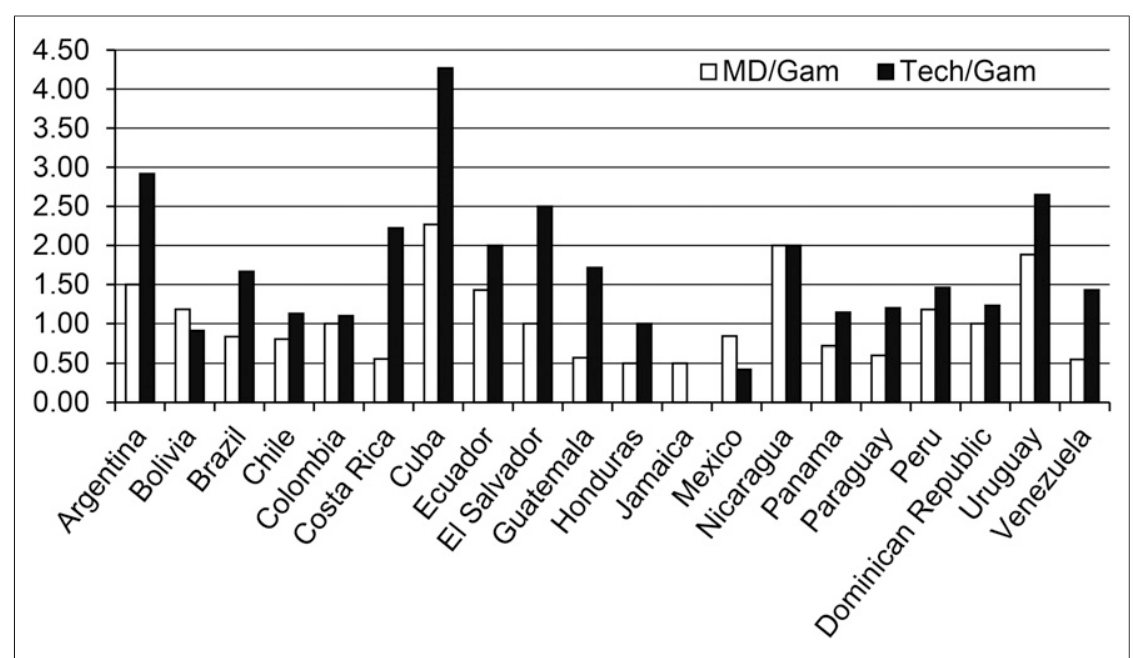

FIGURE 3. NM physicians (MD) and technologists (Tech) per y camera (Gam).

most cases. These professionals have contributed to the development of radiopharmacy in the region and the implementation of research activities in this field, as well as the availability of cold kits and PET tracers. In countries without regular training programs, professionals have received their training abroad.

\section{Continuing Education}

Besides national educational programs, all professions involved in the practice of NM have many educational opportunities through activities organized or sponsored by the IAEA as well as local or regional scientific societies such as the LatinAmerican Association of Biology and Nuclear Medicine (ALASBIMN), which has a continuing education committee that organizes regular training courses during

program. Feedback has indicated a significant gain in knowledge, the development of problem-solving skills, and, most importantly, a positive change in attitude and practice.

\section{Physicists}

Medical physicists have proved to be key members of the NM department because of their training in quality control and their general scientific approach to problems. They usually participate in several tasks (9), such as the establishment of institutional radiation protection programs, quality control of NM instruments, and optimization of NM clinical procedures, including acquisition and processing protocols. More recently they have increased their activities by introducing clinical dosimetry to medical practice, in order to optimize radionuclide therapy in different clinical scenarios. Many postgraduate educational activities on these topics have taken place in the region, with most being sponsored by the IAEA.

However, there is an overall shortage of medical physicists with NM training in the region. Only 12 of 21 ARCAL Member States have medical physicists working in NM, with 0.1 medical physicist per center. Argentina, Brazil, Cuba, and Venezuela are the countries with the largest number of physicists, but only the last two have almost one professional per NM department (Fig. 4). Some countries have postgraduate educational programs in medical physics, namely Argentina, Brazil, Chile, Costa Rica, Cuba, Colombia, Mexico, and Venezuela. Training programs have increased in the last few years, but the number of graduates does not meet the need. The medical physicist is generally not recognized as a member of the health care team, and formal positions are usually nonexistent in most hospitals and institutions despite the need for their expertise in a variety of technical tasks. Most medical physicists tend to dedicate themselves to other areas with more solid demand and better remuneration, such as radiotherapy.

\section{Radiopharmacists and Radiochemists}

There are approximately 122 radiopharmacists and radiochemists in the region, distributed in 11 countries. This number corresponds to 0.1 radiopharmacist or radiochemist per center (Fig. 4), a number that is far from ideal to cover the regional need. Some Member States have strong university programs, as is the case in Argentina, Brazil, Costa Rica, Cuba, Mexico, and Uruguay, with graduates having access to master's or $\mathrm{PhD}$ degrees in the congress that takes place every 2 years in different locations across the region.

The IAEA has played a relevant role in the improvement of human resources, sponsoring many regional and national training courses covering a wide variety of topics such as the basic sciences, technical and clinical issues, radiopharmacy, radiation safety, and quality management. A large number of NM professionals have been supported by the IAEA for training activities such as international fellowships and scientific visits. More recently, the IAEA established cooperation agreements and strategic partnerships with important international organizations such as the World Federation of Nuclear Medicine and Biology (WFNMB), the Society of Nuclear Medicine and Molecular Imaging, the European Society of Nuclear Medicine and Molecular Imaging, and the American Society of Nuclear Cardiology and has facilitated access for over 400 professionals to online training in diagnostic CT and PET/CT and for over 1,000 participants from the region to webinars and other continuing medical education activities. It is expected that these educational activities will soon expand, reaching a broader range of professionals in the region.

\section{TYPES OF PROCEDURES}

Data obtained from NUMDAB, which represents about $10 \%$ of all NM departments in the region, show that nearly $90 \%$ of procedures performed in a typical setting are diagnostic NM procedures, excluding PET and PET/CT. Bone and cardiac studies are the most common procedures, at an average of $30 \%$ and $21 \%$, respectively, followed by endocrine and renal studies (Fig. 5). PET applications are growing quickly; they currently represent about $4 \%$ of total NM. Although not specifically mentioned in the graphs, sentinel node detection is growing rapidly as it gains acceptance among surgeons and oncologists. Regarding therapeutic applications, which account for $6 \%$ of procedures, most involve the use of radioiodine for thyroid cancer and hyperthyroidism. However, there is increased use of new therapeutic agents such as ${ }^{131}$ I-metaiodobenzylguanidine, somatostatin peptide analogs labeled with ${ }^{177} \mathrm{Lu}$ or ${ }^{90} \mathrm{Y}$ for neuroendocrine tumors, ${ }^{90} \mathrm{Y}$ - or ${ }^{131}$ I-labeled anti-CD20 monoclonal antibodies for lymphoma, and an $\alpha$-emitter $\left({ }^{223} \mathrm{Ra}\right)$ for metastatic castration-resistant prostate cancer. 


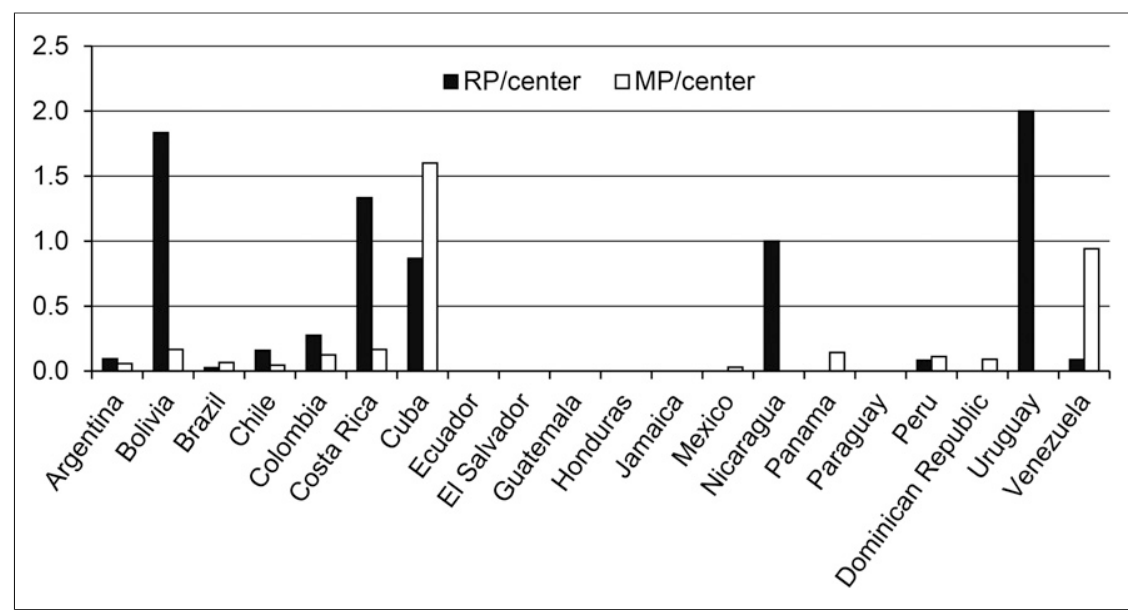

FIGURE 4. Nuclear physicists (MP) and radiopharmacists (RP) per center. an award for the best abstract in oncology coming from a Latin American country.

Although limited, there is a preclinical imaging infrastructure for animal studies: 1 PET-SPECT/CT camera and 1 PET camera in Mexico, 8 PET-SPECT/CT cameras in Brazil, and 1 PET-SPECT/CT camera in Uruguay.

\section{QUALITY PRACTICE}

Beside the national plans and regulations in some countries related to implementation of quality management in clinical practice, an effort to expand and consolidate quality practice in NM has been developed by the IAEA. A quality audit program, QUANUM (Quality Management Audits in Nuclear Medicine Practices) (10), based on guidelines prepared by experts in the field has been implemented. With the support of IAEA, multidisciplinary auditor teams have been trained, with the involvement of regional experts who have conducted audit missions to various countries at the request of institutions. The aim of the audits is to identify problematic areas and to advise on how to improve the quality of practice. Up-to-date quality management systems in NM services have been implemented in most ARCAL Member States, and over 1,000 NM professionals have received training in this field. region convene to share the latest advances in NM and molecular imaging. ALASBIMN has its own official peer-reviewed, open-access, online publication, ALASBIMN Journal (www. alasbimnjournal.net), which accepts articles in Spanish, Portuguese, or English.

\section{RESEARCH}

Even though many centers in the region have participated in research coordinated by the IAEA, most are at universities. The number of regional authors who publish in peer-reviewed journals and present at international meetings is relatively low. ALASBIMN encourages the presentation of research papers by issuing 4 types of awards for the best abstracts in basic and clinical sciences, as well as for technologists and young investigators, respectively. Since 2012, the Society of Nuclear Medicine and Molecular Imaging has offered

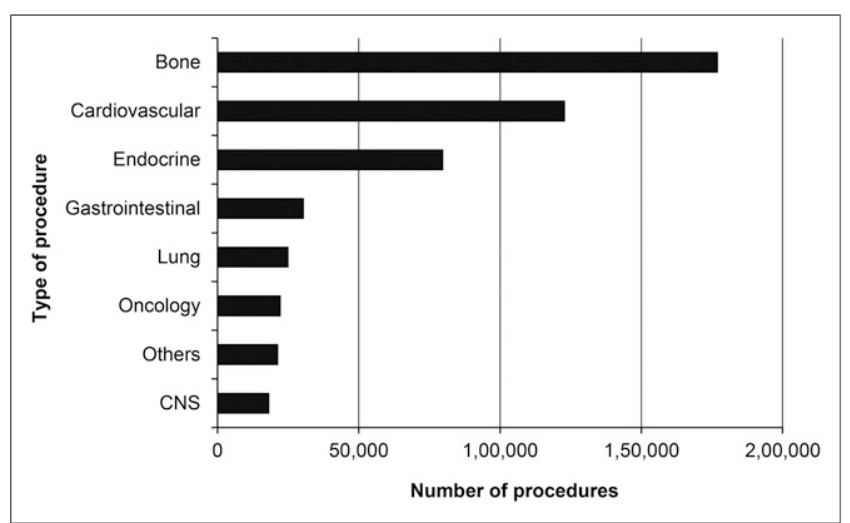

FIGURE 5. Types of NM procedures (excluding PET) and annual number (data from NUMDAB).

\section{DISCUSSION}

The average number of $\gamma$ cameras per million people in the region is 2.6, with a range of 0.0-6.7. This is lower than in Europe (average, 5.57; range, 0.0-26.46), the United States (47.2), or Canada (21.05), according to data from the World Health Organization (https://www.quandl.com/data/WHO). The analysis of the status of NM in the Latin American and Caribbean region leads to several observations. Some strengths can be identified, such as the availability of almost all current diagnostic and therapeutic applications of the specialty, endowing the region with the possibility of providing NM services in line with international standards. This strength is supported by a progressive growth of technology, with a clear trend toward modernization of existing infrastructure. In some countries, there is specific governmental support for the use of nuclear techniques in health care systems, and there is interest in both the public and the private sectors to invest in this area as a tool to confront some of the most prevalent diseases (11). In addition, a significant number of well-qualified, highly competent experts are available in the region, and high-level university training centers are able to provide specialized education to fellows in all areas of the specialty. These strengths are reinforced through horizontal cooperation among countries, especially in the development of human resources and the supply of consumables and radiotracers.

Several interinstitutional, national, and international agreements have improved bilateral cooperation among countries, as evidenced by the activities of scientific societies that play an important role in educational and strategic support, mainly through the organization of regular scientific events and continuing medical education activities. A key aspect has been the use of a common language among most countries in the region, which 
facilitates scientific exchange, information access, and continuing education. The IAEA has been playing a pivotal role in supporting the development and improvement of NM-including infrastructure, equipment, and human resources-as part of national and regional technical cooperation projects.

Some weaknesses can also be observed. Access to NM procedures is not equal among countries or even within a country, with wealthy countries and individuals having greater access. Also, there is clearly a concentration of resources in capitals and large urban communities. The lack of national production of radiopharmaceuticals, radioisotopes, and other consumables has limited the use of NM techniques in some countries because of high import costs and limited availability.

Some key challenges in the region are to identify factors that hinder growth of the specialty, propose active and open collaboration among regulators and the NM community, and promote coverage of NM procedures by health care systems. A limitation is the difficulty of complying with international standards, particularly because of the lack of harmonization across the region in infrastructure, machinery, quality management, availability of radiotracers, and qualified personnel.

Another challenge is the difficulty of coping with the training needs of the multidisciplinary team of professionals, namely physicians, medical physicists, technicians, radiographers, and radiochemists. Although training exists, there are significant differences in the curricula of training programs for physicians and technologists and there is a scarcity of formal training for medical physicists and radiopharmacists. There is also a shortage of highly specialized personnel to effectively manage complex equipment such as cyclotrons and hybrid systems (SPECT/CT and PET/CT).

Even though obsolescence of medical equipment is a problem in some countries, that issue has improved through equipment replacement programs. However, lack of proper assessment of the impact of introducing novel, high-cost health technologies and their sustainability can increase health care costs.

At present, the specialty clearly has opportunities. Demographic and epidemiologic transition in the region generates the need for diagnostic and therapeutic NM procedures to provide cost-effective management of prevalent diseases, particularly cancer and cardiovascular diseases. In addition, economic growth is expected to continue, allowing investment in state-of-the-art technology and introduction of novel radionuclide therapies. NM professionals have educational opportunities based on ongoing national and international efforts. The development of information and communication technology will continue to be a key factor in training and in the development of competencies to meet future human resource requirements.

\section{CONCLUSION}

The future of NM in the Latin American and Caribbean region is promising, with great potential and possibilities. To drive the region toward greater homogeneity in the availability and application of NM, it is important to identify and acknowledge crucial factors preventing bridging of the gaps within the region and within individual countries. Our data, and the experience of experts in the field, show that the factors most fundamental to enabling communities to take advantage of the benefits of NM are clinician awareness of its importance in managing diseases in the region, increased building of capacity, continuous and strong support from international organizations such as the IAEA through national and regional projects, and strong public-private partnerships and government commitment. It is essential to build the capacity of NM in this region. A systematic, integrated approach must be sought to develop and continuously improve governmental, organizational, and individual competence in order to achieve effective, efficient, safe, and sustainable use of current and futures advances in NM.

\section{DISCLOSURE}

The costs of publication of this article were defrayed in part by the payment of page charges. Therefore, and solely to indicate this fact, this article is hereby marked "advertisement" in accordance with 18 USC section 1734 . No potential conflict of interest relevant to this article was reported.

\section{REFERENCES}

1. Economic Survey of Latin America and the Caribbean 2013: three decades of uneven and unstable growth. Economic Commission for Latin American and the Caribbean website. http://www.cepal.org/en/publications/economic-surveylatin-america-and-caribbean-2013-three-decades-uneven-and-unstable. Published January 2014. Accessed August 19, 2015.

2. Global Health Observatory Data Repository. Geneva, Switzerland: World Health Organization; October 2013.

3. Health situation in the Americas: basic indicators-2012. Pan American Health Organization website. http://ais.paho.org/chi/brochures/2012/BI_2012_ENG.pdf. Published 2012. Accessed August 19, 2015.

4. Regional strategic profile for Latin America and the Caribbean (RSP) 20072013. ARCAL website. http://www.arcal-lac.org/images/documentos/per2007eng/1_E_Regional\%20Strategic\%20Prole.pdf. Published August 2008. Accessed August 19, 2015.

5. Dondi M, Kashyap R, Paez D, et al. Trend in nuclear medicine in developing countries. J Nucl Med. 2011;52(suppl):16S-23S.

6. Kashyap R, Dondi M, Paez D, Mariani G. Hybrid imaging worldwide: challenges and opportunities for the developing world: a report of a technical meeting organized by the IAEA. Semin Nucl Med. 2013;43:208-223.

7. Operational guidance on hospital radiopharmacy: a safe and effective approach. International Atomic Energy Agency website. http://www-pub.iaea.org/MTCD/ publications/PDF/Pub1342/Pub1342_web.pdf. Published 2008. Accessed August $19,2015$.

8. Patterson HE, Nunez M, Philoteou GM, Hutton BF. Meeting the challenges of global nuclear medicine technologists training in the 21st century: the IAEA Distance Assisted Training (DAT) program. Semin Nucl Med. 2013; 43:195-201.

9. Roles and responsibilities, and education and training requirements for clinically qualified medical physicists. IAEA Human Health Series No. 25. International Atomic Energy Agency website. http://www-pub.iaea.org/MTCD/Publications/ PDF/Pub1610_web.pdf. Published August 2013. Accessed August 19, 2015.

10. Quality management audits in nuclear medicine practices. International Atomic Energy Agency website. http://www-pub.iaea.org/MTCD/publications/PDF/ Pub1371_web.pdf. Published 2008. Accessed August 19, 2015.

11. Casas-Zamora JA, Kashyap R. The IAEA technical cooperation programme and nuclear medicine in the developing world: objectives, trends and contributions. Semin Nucl Med. 2013;43:172-180. 